Portland State University

PDXScholar

8-10-1995

\title{
The Health Belief Model as a Predictor of Gynecological Exams: Does Sexual Orientation Matter?
}

Lynn Elizabeth Kunkel

Portland State University

Follow this and additional works at: https://pdxscholar.library.pdx.edu/open_access_etds

Part of the Psychology Commons

Let us know how access to this document benefits you.

\section{Recommended Citation}

Kunkel, Lynn Elizabeth, "The Health Belief Model as a Predictor of Gynecological Exams: Does Sexual Orientation Matter?" (1995). Dissertations and Theses. Paper 4943.

https://doi.org/10.15760/etd.6819

This Thesis is brought to you for free and open access. It has been accepted for inclusion in Dissertations and Theses by an authorized administrator of PDXScholar. Please contact us if we can make this document more accessible: pdxscholar@pdx.edu. 


\section{THESIS APPROVAL}

The abstract and thesis of Lynn Elizabeth Kunkel for the Master of Science in

Psychology were presented August 10,1995 and accepted by the thesis committee

and the department.

COMMITTEE APPROVALS:

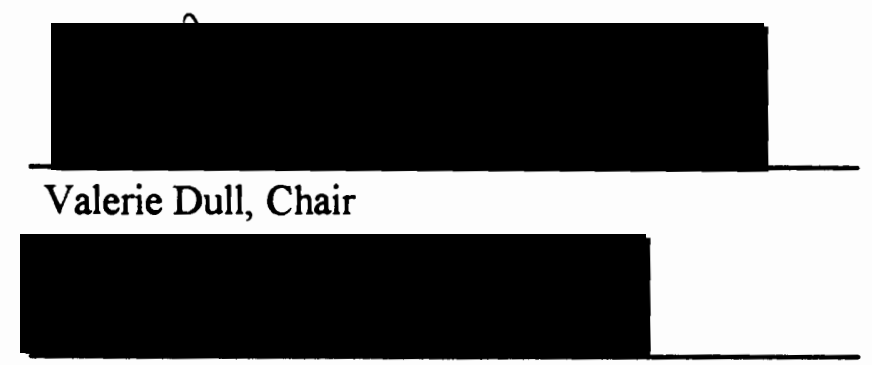

James Paulson

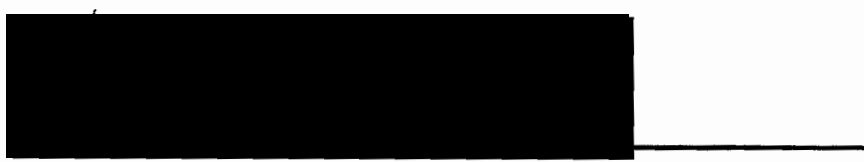

Leslie McBride

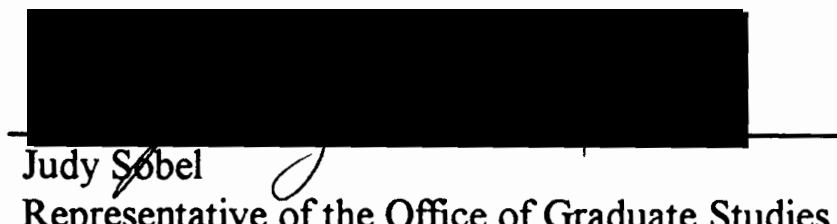

Representative of the Office of Graduate Studies

DEPARTMENT APPROVAL:

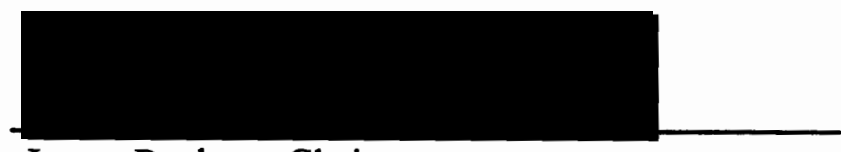

James Paulson, Chair

Department of Psychology 


\begin{abstract}
An abstract of the thesis of Lynn Elizabeth Kunkel for the Master of Science in Psychology presented August 10, 1995.
\end{abstract}

Title: The Health Belief Model as a Predictor of Gynecological Exams: Does Sexual Orientation Matter?

Screening and early detection are essential for the management and control of most diseases. It is important for women to practice routine health care that includes both clinical and self examinations. Today, many women go without health care due to barriers which prevent them from obtaining adequate care. The present study was designed to investigate, using the Health Belief Model, whether there is a difference between heterosexual and lesbian women in obtaining gynecological exams. Responses from 238 participants, 70 heterosexuals and 168 lesbians, indicated that the Health Belief Model was a significant predictor of whether women complied with recommended guidelines for Pap smears. Further analyses indicated that the most predictive components of the model were selfefficacy and perceived barriers. The more self-efficacy the women reported, the more likely they were to comply; whereas, the more barriers the women reported, the less likely they were to comply. Surprisingly, there were no interactions between sexual orientation and the components of the Health Belief Model with 
respect to compliance. Thus, the model predicts compliance in the same way for both lesbian and heterosexual women. The results are consistent with past research indicating that the Health Belief Model is a good predictor of health behavior for some groups. Suggestions for future studies are discussed. 
THE HEALTH BELIEF MODEL AS A PREDICTOR OF GYNECOLOGICAL EXAMS:

DOES SEXUAL ORIENTATION MATTER?

by
LYNN ELIZABETH KUNKEL

A thesis submitted in partial fulfillment of the requirements for the degree of

\author{
MASTER OF SCIENCE \\ in \\ PSYCHOLOGY
}

Portland State University

1995 


\section{Acknowledgments}

There are many people for whom I would like to thank for their time and efforts in assisting me with this thesis:

- My committee chair, Dr. Valerie Dull, for taking a chance on me and going beyond the call of duty.

- Dr. Leslie McBride, for providing a different perspective of wisdom, for making me feel like what I was doing was important and that I could accomplish it.

- Dr. James Paulson, for putting up with, and challenging me, during my statistical struggles.

- Dr. Judy Sobel, the graduate representative, for taking time out of her summer so that I could defend this thesis.

- Dr. Laurie Skokan, for the countless hours of "ghost" advising which impacted the study such that it would not have been the same without her assistance.

- Penny Stirling, for providing the access to the lesbian participants and for understanding the importance of this topic with such a special population.

- Dr. Don Diener, the UNLV Subject Pool, and Heather Hern for their assistance in obtaining the heterosexual participants.

- Dr. William Feyerherm, for assisting me with the data collection.

Finally, I would like to dedicate this thesis to my LP. Without the support, unconditional love, and understanding of the countless hours of distractions and frustrations, this could not have been completed. You have given me a strength and inner peace that has seen me through the setbacks and successes of graduate school and this project. I thank you for that and for everything with which you provide me. 
The Health Belief Model as a Predictor of Gynecological Exams:

\section{Does Sexual Orientation Matter?}

Over much of the twentieth century the medical community has focused its attention on controlling and curing diseases. Yet, gradually, focus has shifted toward disease prevention rather than disease treatment (Bernard \& Krupat, 1994). This may be due to the fact that patterns of ilmess affecting people have changed. According to Sarafino (1994), the main health problems in advanced technological societies are no longer acute, infectious diseases, they are chronic diseases such as heart disease, diabetes, and some forms of cancer. Although there has been a great deal of progress in understanding the causes of such chronic diseases, the actual improvements in techniques for treatment have been modest. For example, the General Accounting Office reported in 1987 that the gaims in cancer survival rates among patients since 1950 resulted not from medical techniques as much as from other factors, mainly early detection of the disease (Boffey, as cited in Sarafmo, 1994). Although medical science has made tremendous advances in controlling and curing disease, it appears that the best treatment for diseases is early detection.

Since early detection is essential for the management and control of most diseases, it is especially pertinent that routine health care include both clinical and self examinations. The present study was designed to focus on preventive medical procedures (i.e., screening and early detection) and to identify the barriers that may 
keep women from participating in these procedures, specifically gynecological screening.

\section{Screening and Early Detection}

Medical science and technology have made great progress in treating diseases. However, according to public health expert Lester Breslow, "the principal advances in health have come about through health promotion and disease prevention rather than through diagnosis and therapy" (Sarafino, 1994).

The concept of prevention pervades all activities in health management and control since it is the first defense against illmess. It is common to distinguish among three forms of prevention; primary, secondary, and tertiary. Primary prevention refers to efforts to reduce or eliminate exposures to risk behaviors or objects in order to prevent the initiation or promotion of the fundamental disease process. Examples of primary prevention include obtaining immunizations against contagious diseases, resisting tobacco use, exercising, and eating a healthy diet. Secondary prevention includes screening and early detection programs that seek to identify diseases early in their development, so that the chances for cure are enhanced. Examples of secondary prevention include blood pressure measurements, routine physicals, and routine gynecological examinations. Tertiary prevention refers to the treatment of patients in order to prevent undue clinical complications or premature death (Holleb, Fink, \& Murphy, 1991). This form of prevention is usually in effect when a serious injury or a disease has progressed beyond early stages and requires action to contain or retard the 
damage, prevent disability, or rehabilitate the patient (Sarafino, 1994). Examples are physical therapy and taking medications to control pain or inflammation. Although all of these forms of prevention are important, the focus of the present study will be on secondary prevention, namely screening and early detection.

According to the American Cancer Society, screening is defined as the search for disease in asymptomatic people. An asymptomatic person is one who does not have symptoms which are related to a disease. Once an individual has a positive screening test, or once signs or symptoms have been detected, further tests are considered diagnostic, not screening. Therefore, while screening looks for disease in people without symptoms, detection is defined as the discovery of an abnormality in either an asymptomatic or symptomatic person (Holleb, Fink, \& Murphy, 1991).

Results of numerous studies (Norman et al., 1991; White, 1993; Yoder \& Rubin, 1992) have shown that screening and early detection provide an opportunity to implement treatments that can either slow down the progress of a disease (such as with chemotherapy) or remove the cells which represent the disease. If diseases go undetected or untreated, they may result in serious complications such as infertility or death.

One form of screening which is performed in routine gynecological exams, and is the focus of this study, is the Papanicolaou (Pap) smear. This procedure, which involves testing a sample of cervical cells, can detect malignant cells as well as other cells which may identify sexually transmitted diseases and infections (Holleb, Fink, \& 
Murphy, 1991). The Pap smear is one of the most important exams for asymptomatic women because it may be the first indication to the patient of any problem (White, 1993). To date, the Pap smear is the single most effective method for identifying irregularities in cervical cells. Coupled with a pelvic exam, the Pap smear is a life-saving procedure. Overall, the death rate from uterine cervical cancer has decreased more than $70 \%$ during the last 40 years, mainly due to the Pap smear and routine checkups (Holleb, Fink, \& Murphy).

Four Theories of Health Behavior

There are several theories that have been proposed to explain the adoption of health related behavior. Despite a large empirical literature, there is no consensus that certain models of health behavior are more accurate than others, that certain variables are more influential than others, or that certain behaviors or situations are understood better than others (Weinstein, 1993).

In general, there are four competing theories that are used more frequently than others to explain protective health behaviors. These four theories are subjective expected utility theory (Ronis, 1992), protection motivation theory (Maddux \& Rogers, 1983; Prentice-Dunn \& Rogers, 1986), the theory of reasoned action (Ajzen \& Fishbein, 1980; Fishbein \& Ajzen, 1975), and the health belief model (Janz \& Becker, 1984). Although there are many similarities among these four theories, each one has unique strengths and weaknesses (for complete review see Weinstein, 1993). 
In short, subjective expected utility theory postulates a simple mathematical model of decision making in which people evaluate the expected utility (desirability) of alternative actions and select the action with the highest subjective expected utility. This theory makes specific predictions about the relations among beliefs and the relations between beliefs and behaviors. However, this theory does not specify which outcomes or beliefs are most relevant to a given decision (Ronis, 1992).

Protection motivation theory maintains that the motivation to protect one's self from a health threat is based on four beliefs: 1 ) the threat is severe (magnitude of threat);2) one is personally vulnerable to the threat; 3 ) one is able to perform the response needed to reduce the threat (self-efficacy); and 4) the response will be effective in overcoming the threat (response efficacy). According to this model, when beliefs about these four factors are strong, then protection motivation is aroused, and individuals are more likely to change their attitudes toward and practice a health behavior (Taylor, 1991).

The theory of reasoned action was proposed to explain how cognitive factors predict behavior. According to the theory, intentions causally determine behavior and in turn, intentions are caused by the joint influences of attitudes toward the behavior and subjective norms (McCaul, Sandgren, ONeill, \& Hinsz, 1993). This theory is different from the other three theories in that it incorporates social influence. Subjective norms can be described in terms of the extent to which other relevant 
people want the individual to perform a given behavior and how much the individual is motivated to comply with each of their preferences (Weinstein, 1993).

The value of a particular theory lies in the ability of its variables and their interrelationships to address the specific real-world phenomena of interest to the researcher and the ability of the theory to answer the questions posed by a specific problem. Considering the topic of interest and the questions of this study, the Health Belief Model, discussed below, has the constructs which are most comprehensive for the questions of interest and will therefore be used to examine gynecological screening.

\section{Health Belief Model}

The Health Belief Model (HBM) was developed by Hochbaum, Kegeles, Leventhal, and Rosenstock in the 1950's to explain health-related behavior at the level of individual decision making (Mikhail, 1981). According to Mikhail, the model is a psychosocial formulation developed to deal with questions such as, Why do some people use health services but others do not? What are the factors that prevent or interfere with following health care recommendations? How can health-related behavior be changed when necessary?

The basic components of the HBM are derived from a body of psychological and behavioral theory whose models hypothesize that two primary variables determine behavior: (1) the value placed by an individual on a particular goal and (2) the individual's estimate of the likelihood that a given action will achieve that goal. When 
these variables were conceptualized into health-related behavior, the components were: (1) the desire to avoid illness; and (2) the belief that a specific health action will prevent illhess (Janz \& Becker, 1984).

The likelihood that a person will take action and practice a particular health behavior is determined by the degree to which the individual perceives a personal health threat and the perception that a particular health practice will be effective in reducing that threat. According to Taylor (1991), the perception of a personal health threat is itself influenced by at least three factors: general health values, which inchude both interest and concem about ones health; specific beliefs about vulnerability to a particular disorder or disease; and beliefs about the consequences of the disorder (whether or not they are serious).

Whether or not the perception of a health threat leads to a change in behavior depends on whether a person believes a health practice will reduce that threat. Taylor (1991) suggests that these factors break down into two subcomponents: whether or not the individual thimks a particular health practice will be effective against the disorder in question; and whether or not the cost of undertaking that practice exceeds the benefits of the practice. Becker and Maiman (1975) have shown that even if an individual is ready to act, the likelihood of taking action will depend on beliefs about the probable effectiveness of the action in reducing the health threat and on the difficulties that must be encountered if such action is taken. According to Mikhail (1981), a perceived benefit of performing a behavior is the individual's evaluation of 
the behavior in terms of its feasibility and efficacy in reducing the threat (perceived susceptibility to and/or severity of the condition). The perceived benefits of an action are weighed against the perceived psychological, physical, financial, and any other cost / barriers which may exist in taking the action.

The original HBM consists of the following components:

1) Perceived susceptibility. Since individuals vary widely in their feelings of personal vulnerability to a condition, this component refers to one's subjective perception of the risk of contracting a condition.

2) Perceived severity. This component refers to feelings concerning the seriousness of contracting an illness (or of leaving it untreated). Evaluations of both medical/clinical consequences (e.g., disability and pain) and possible social consequences (e.g., family life, and social relations) are included in this dimension. 3) Perceived benefits. This component refers to whether the individual believes that the recommended action is effective in preventing, detecting, or treating the condition and thus reduces its threat.

4) Perceived barriers/costs. This component refers to the potential negative aspects of the recommended health action.

The HBM has been revised and expanded several times. The key variables in the most recent version of the model, which will be used in this study, are illustrated in Figure 1. The variables which were added to the model involve beliefs about the nature of the threat (perceived threat), belief's about the nature of the action (efficacy 
of behavior), and belief s about one's abilities to accomplish relevant action (self-efficacy) (Bernard \& Krupat, 1994).

1) Perceived threat. Perceived threat is composed of the two original elements of perceived susceptibility and perceived severity. The HBM predicts that when the severity and susceptibility are both high, the person will be motivated to take action to deal with the threat of their health (Bernard \& Krupat, 1994).

2) Efficacy of the behavior. Efficacy of the behavior involves the original elements of perceived benefits and perceived barriers. To choose among alternative courses of action, the HBM suggests that people go through a form of mental cost-benefit analysis. In choosing among several options, people weigh the perceived benefits of the action against its perceived barriers (costs), choosing the path that maximizes the net result of gains minus costs (Bernard \& Krupat, 1994). People take action when they feel it is likely to work. When multiple possibilities are available, they select the one they believe will work best.

3) Self-efficacy. Self-efficacy is the last factor which is an addition to the HBM. This addition focuses on Bandura's concept of self-efficacy. Self-efficacy refers to the belief that individuals can successfully accomplish the action required to achieve a goal. Studies have indicated that people who have high levels of self-efficacy are more likely to initiate and maintain a program of behavior change (Bandura, 1986). 
Along with the addition of self-efficacy, the HBM has incorporated other variables throughout its history. Most important among these are demographic variables, personality characteristics, knowledge about and interest in health, and past experience. Each of these may serve as modifiers of perceived threat. Another addition, which has been included in some versions of the HBM, is the variable cues to action. This construct, which in the literature has been considered necessary to trigger a given response, may be either internal, external (Bernard \& Krupat, 1994; Mikhail, 1981), or self-initiated (Bausell, 1986).

For decades, the HBM has been used as a major organizing framework for explaining and predicting the acceptance of health and medical care recommendations (Janz \& Becker, 1984). Studies utilizing the HBM include breast self-examination (Champion, 1990), mammography screening (Stein, Fox, Murata, \& Morisky, 1992), dental flossing behavior (Ronis, 1992), smoking and dieting for obesity (Janz \& Becker, 1984), among many others (Taylor, 1991). Janz and Becker examined 46 studies between the years 1974-1984 which used the HBM to identify which components best predict the practice of health behaviors. Their meta-analysis revealed that perceived barriers to the practice of the health behavior was the most powerful component influencing whether people actually practiced a particular health behavior (for complete review see Janz \& Becker, 1984). More recently, Harrison and his colleagues (1992) conducted a meta-analysis of the relationships between the original 
four HBM components and health behaviors in 16 studies. Their results indicated significant positive relationships between HBM components and health beliefs.

However, not all research supports the HBM (Hester \& Macrina, 1985; Kirscht, 1983; Taylor, 1991). One of the problems with the model is that the variables are often operationalized differently by investigators (Hester \& Macrina). Thus, different questions are used in different studies to assess the same beliefs.

Consequently, it is difficult both to design appropriate tests and to compare results across studies. Another problem with the HBM is that factors other than health beliefs may also heavily influence the practice of health behaviors. These factors may include social influences, cultural factors, experience with a particular health behavior or symptom and socioeconomic status (Kirscht).

Overall, the HBM seems to be the best model to explain the general health behaviors of people who are knowledgeable about health matters and have a high socioeconomic status. That is, people who have financial resources and people who are knowledgeable about health issues are more likely to practice good health habits than other people. Thus, the HBM appears to predict health behaviors best when demographics (e.g., sex and education) have been controlled (Taylor, 1991).

There has been much research using the HBM to predict mammography screening and breast self-examination. However, these behaviors will not be discussed here since they are viewed as separate behaviors from a gynecological exam, even though they are often conducted in the same climical environment. Although these 
behaviors are important, the exclusion of these exams in this project is due to the large existing literature pertaining to these behaviors and the importance of investigating screening and early detection that relates directly to cervical exams.

There has been limited research investigating the applicability of the HBM to obtaining regular gynecological exams, including a Pap smear. Knopf (1976) indicated that older women and working class women were the least likely to have a Pap smear, and the two most frequently identified reasons for why they failed to obtain one were embarrassment and fear of discovering a cancer. O'Brien and Lee (1990) conducted a study to assess the capacity of modeling videotapes to promote Pap smear screening. Consistent with the earlier work of Knopf, the predomimant barriers inchuded feeling awkward and embarrassed, concern about physical discomfort, and worry about possible results. Furthermore, results indicated that the variables of the HBM accounted for $25 \%$ of the variance in the respondents' behaviors associated with obtaining Pap smears. Perceived benefits, perceived barriers and perceived susceptibility were the most important predictors. Overall, the HBM, particularly perceived barriers, was a good model to predict Pap smear behavior. Similarly, Murray and McMillan (1993) tested the HBM and locus of control for cancer screening behavior. They also found that perceived barriers to health care was identified as the most important predictor of obtaining cervical screening. Their results indicated that women who perceived fewer barriers were more likely to be screened. Further, the barriers they found to have the highest negative correlation 
with attendance were embarrassment, indignity, discomfort, fear of result and doctor's fee. Overall, the most important barrier was fear of becoming a burden to the family. As a means of reducing this threat, the results indicated that these women would prefer not to know if there is something wrong.

\section{Lesbian Health Care}

The delivery and accessibility of health care services are extremely important in the context of sociopolitical issues today (Robertson, 1992). There are many minorities who are struggling to maintain adequate health care. Among these minorities are lesbians. Lesbians may be considered an invisible minority since sexual identity is a psychosocially defmed identity and not a physically observable status. A health care provider may not realize that a patient is a lesbian since there are no distinguishing physical characteristics of a female homosexual and since sexual orientation cannot be determined by a physical exam. This creates unique challenges for the medical profession in providing adequate services to lesbians.

Furthermore, the health care concerns of lesbians differ from those of heterosexual women (Robertson, 1992). Lesbians have been found to have a slightly higher risk for the delayed detection of cervical dysplasia. Also, they may be at increased risk for breast and endometrial cancer due to their high incidence of nulliparity (having borne no children) (Lucas, 1992). If lesbian health concerns are different from those of heterosexual women, and if lesbians are not identified by the 
medical profession, this implies that the health needs of lesbians may be overlooked (Buenting, 1992).

Past literature has suggested that lesbians avoid obtaining traditional health care services by never going or making infrequent visits (Robertson, 1992; Stevens, 1994, 1992; Trippet \& Bain, 1992, 1990). There may be many factors which contribute to such avoidance (for complete review see Stevens, 1992). One of these factors may be that the traditional health care system has based its care and treatment of women on assumptions of heterosexuality (Dardick \& Grady, 1980; Stevens, 1992; Robertson; Johnson, Guenther, Laube, \& Keettel, 1981). The assumption is that, unless otherwise stated, all women are heterosexual (Dardick \& Grady; Johnson \& Palermo, 1984; Stevens, 1992; Robertson). Studies have shown that medical history forms and patient interview questions assume heterosexuality. These forms often lead to inaccurate and incomplete information with regard to lesbians (Johnson \& Palermo). Assumptions of heterosexuality may set up barriers for lesbian patients (White \& Levinson, 1993), especially the topic of sexual activity. Typically, the patient is asked if she is sexually active and if so, what form of birth control she uses (Robertson). Other studies have shown that lesbians are often put off by the language of the questions pertaining to marital status, birth control, and sexual activity (Dardick \& Grady; Johnson \& Palermo).

Numerous other studies have documented that lesbians avoid or delay seeking health care because of insensitivity of health care personnel and because the medical 
system relates poorly to their sexual preference (Johnson, Guenther, Laube, \& Keettel, 1981; Smith, Johnson, \& Guenther, 1985; Stevens \& Hall, 1988; Zeidenstein, 1990). Bad experiences with health care professionals have been found to make lesbian patients more likely to terminate care and avoid routine screening (White \& Levinson, 1993). Johnson and Palermo (1984) found that $40 \%$ of their subjects indicated that they feared their care would be negatively affected if they revealed their sexual orientation and some of the subjects felt harassed by the lack of sensitivity to alternative lifestyles exhibited during birth control counseling. In turn, many lesbians are reluctant to share their sexual orientation with physicians for fear of negative judgments and homophobia (White \& Levinson). Trippet and Bain (1992) indicated that lesbians failed to seek traditional health care because of fear of discrimination or actual experiences of discrimination from health providers.

Another barrier which may influence lesbians to avoid seeking medical care is the decision about whether to disclose their sexual orientation ("come out") to the health professional (Stevens, 1992). Stevens and Hall (1988) found that $72 \%$ of their respondents had experienced a negative reaction when they disclosed their sexual preference. More recently, Zeidenstein (1990) found that the fear and discomfort of coming out to health professionals influenced the majority of her subjects to postpone their gynecological care or seek lesbian-sensitive health care providers. Further, her results indicated that those who did choose to come out did so to dispute the health 
care provider's heterosexual assumptions, such as assuming the client had a need for birth control or that the sexual partner of the client was male.

Economic barriers to health care have also been identified as barriers for lesbians (Stevens, 1992; Stevens \& Hall, 1988). According to Stevens, financial access to care is problematic for women who live outside heterosexually constructed nuclear families, unattached to adult male incomes and insurance coverage. Female workers in the United States are paid inequitable wages, receive less extensive health benefits, and are more likely to be without health coverage of any kind. Since most lesbians cannot claim partners on health insurance policies, many lesbians may not have health coverage.

Information may be another barrier which may be preventing lesbians from obtaining gynecological exams. There may be a misperception among lesbians that regular Pap smears are unnecessary unless one is heterosexually active (Buenting, 1992), is in need of birth control, or is having menstrual difficulties.

\section{Present Study}

Despite these efforts to address lesbian health care issues (for complete review see Stevens, 1992), there still remain many gaps in the knowledge of lesbian women's experiences with health care. Although the literature investigating lesbian health care has focused on barriers, there have been limited studies testing whether other variables may be affecting lesbian health care. There have also been few studies which have compared heterosexual and lesbian women using psychological models. Therefore, 
this present study intends to increase understanding of women's health care practices by using the Health Belief Model (HBM) to identify why women do or do not practice health behaviors associated with gynecological exams. Specifically, the study proposes to identify which components of the HBM are most predictive of obtaining gynecological exams for each of these groups of women. Detailed breakdowns between the lesbian group and heterosexual group based on demographics (e.g., education level) are outside the scope of the present study and therefore will not be a major focus.

In light of the available research, the following hypotheses are proposed:

H1: All of the components of the Health Belief Model (HBM), considered simultaneoushy, will significantly predict whether women comply with recommended guidelines for Pap smears.

$\mathrm{H}$ 2: All of the components of the HBM will make unique contributions to whether women comply with recommended guidelines.

H3: Each component of the HBM, considered separately, will be a significant predictor of whether women comply with recommended guidelines.

H4: Considering all of the components of the HBM, barriers will have the strongest correlation with respect to compliance with recommended guidelines.

H5: There will be interactions between all of the components of the HBM and sexual orientation, with respect to compliance with recommended guidelines. 
Methods

\section{Participants}

The lesbian sample consisted of 168 women, between the ages of 18-78 $(\underline{\mathrm{M}}=$ $42.84, \underline{S D}=10.06)$ who volunteered to participate. The participants were obtained through a mailing list from a community center located in a southwestern city. The sample of women varied in educational backgrounds, socioeconomic status, and employment status (see Table 1).

Insert Table 1 about here

The heterosexual sample consisted of 70 women, between the ages of 18-54, $(\underline{M}=31.30, \underline{\mathrm{SD}}=10.93)$, who volunteered to participate. The participants were students enrolled in courses at a middle-sized southwestem university. This sample of women also varied in socioeconomic status and employment status (see Table 1).

\section{Measures}

One questionnaire, containing three parts, was administered to the participants. The first section of the questionnaire contained questions pertaining to the participants' past medical care experiences and activity (see Appendix A). Specifically, the section asked questions regarding health coverage, impressions of medical care, type of medical care patients preferred (allopath, naturopath, etc.), and frequency of medical care and routine exams. 
The next section of the questionnaire, in which participants were asked to rate the extent of their agreement on a seven-point scale, assessed health beliefs. The section was composed of five subsections which assessed the different dimensions of the HBM (see Appendix B). Most of the items were modified from previous research instruments (Champion, 1984; Murray \& McMillan, 1993) and were originally designed to measure each of the five main dimensions of the HBM. The items were slightly modified to measure beliefs about the behavior in question (e.g., the original statement "my chances of getting breast cancer are high" was modified to "my chances of getting cervical cancer are high"). Some items were developed by the researcher in order to measure specific aspects of behavior not addressed in previous studies. The questions pertaining to the dimensions were randomly ordered on the questionnaire. Since the identification of barriers was especially important for the present study, more items were devoted to assessing barriers than to the other components of the HBM (see Appendix C). The final section of the questionnaire contained basic demographic information such as age, relationship status, sexual orientation, education level, income, and employment (see Appendix A).

The questionnaires for the two samples were the same except for three questions which were eliminated from the heterosexual questionnaire (see Appendix D). The questions which did not appear on the heterosexual questionnaire pertained directly to disclosure of sexual orientation to health professionals (e.g., "have you ever disclosed", "what influenced your decision to disclose"), whether health professionals 
are informed about same-sex relationships, and physician preference (e.g., 'if given a choice, would you prefer a female or male physician etc..."). In addition, three barriers and two self-efficacy questions were added to the lesbian questionnaire to assess whether sexual orientation and/or disclosure of sexual orientation influenced obtaining gynecological exams. Thus, both groups received slightly different questionnaires since lesbians were administered more items.

\section{Procedure}

The lesbian participants were obtained through a mailing list to which the experimenters did not have direct access. Instead, the materials were sent to the individual in charge of the list and address labels were added to the envelopes at that stage.

The lesbian participants received the questionnaire through the mail. Enclosed with the questionnaire was a cover letter explaining the purpose of the study and a self-addressed, stamped return envelope. The cover letter contained information regarding the affiliated university through which the study was being conducted, human subjects approval, contact numbers and names of the researchers, and instructions about completing the items. Since the sample was entirely anonymous, no written consent was solicited. Respondents were given a date by which the questionnaire was to be returned. The due date was approximately three weeks from the date of the original mailing. A total of 619 questionnaires were sent to the addresses, four were returned to the sender as "non-deliverable", and 175 were 
returned to the researchers. Three of the questionnaires were returned after the analyses had been performed and were deleted from the sample. Therefore, the response rate was $29 \%$. However, since there was no follow-up to the delivery of the questionnaires, there is no assurance that all questionnaires were delivered to the correct address or the correct individual.

The heterosexual sample was obtained using two different methods. Sixtytwo of the participants were given the questionnaire during a regularly scheduled class period. Twenty-three participants were obtained through a subject pool at the same university. The participants in the subject pool volunteered to participate by signing up for the project and completing the questionnaire at a specific time and place. University policy requires the students to participate in two credit hours of research projects. Participating in this project provided the students with one-half of a credit. Along with the questionnaire, all of the participants were given a cover letter explaining the purpose of the study. The cover letter contained information regarding the affiliated university through which the study was being conducted, human subjects approval, contact numbers and names of the researchers, and instructions on how to fill out the items. Participants were asked to fill out the questionnaire and return it to the experimenter in the mail. A self-addressed stamped envelope was provided. The due date was approximately two weeks from the date that the participant received the questionnaire. Using these two methods, a total of 85 questionnaires were distributed, with 65 returned. The response rate for the heterosexual sample was $78 \%$. 
Results

Initially, the data was edited to be logically consistent. One of the participants who was administered the heterosexual questionnaire indicated that she is a lesbian, and five of the participants who were sent the lesbian questionnaire indicated that they are heterosexual. Collapsing the categories of the sexual orientation variable was also necessary for analysis purposes. Two participants responded that they are asexual and, therefore, were combined with the heterosexual sample. Eleven participants indicated that they are bisexual and were combined with the lesbian sample since these participants may also have to deal with issues involving sexual orientation (e.g., discrimination). After recoding these cases, the final sample consisted of 70 heterosexual questionnaires and 168 lesbian questionnaires.

To assess the reliability of the subscales of the HBM, separate Cronbach's alpha coefficients were computed for each subscale (see Table 2). Considering that

Insert Table 2 about here

the variables of barriers and self-efficacy consisted of a different number of items for lesbians and heterosexuals, it was necessary to compute different Cronbach's alpha coefficients for each group. In order to maximize the internal consistency of the scales for hypotheses testing, individual items from each subscale were evaluated. Items were deleted in three subscales to increase their alpha coefficients. For the severity 
subscale, the item, "Cervical cancer can lead to death if it goes undetected," was dropped to raise the alpha from .68 to .71 . The alpha value for the heterosexual selfefficacy scale was increased from .54 to .61 by dropping the item "I can see a health professional annually even if I have to take time off of school/work". Finally, the subscale for susceptibility was increased from .59 to .67 by dropping the item, "My sexual behavior makes it likely that I will be infected with a sexually transmitted disease". Thus, alpha coefficients ranged from a high of .75 for the lesbian barrier subscale, to a low of .44 for the benefits subscale.

For analysis purposes, the sample was categorized according to whether the women comply with recommended guidelines for Pap smear screening (see Appendix E). Those participants who indicated that they have had two or more Pap smears in the past six years were categorized as women who comply, while women who indicated one or no Pap smears in the past six years were categorized as women who do not comply. To determine compliance of those women between the ages of 18 and 20, a different method of classification was developed since onset of sexual activity is related to compliance for this group (see Appendix F). Analysis indicated that $76 \%$ of the sample complied with the recommended guidelines for Pap smears (see Table 3).

Insert Table 3 about here 
Further analysis indicated that there was not a significant difference between the lesbian and heterosexual participants in regards to compliance with the recommended guidelimes for Pap smears $\left(\mathrm{X}^{2}(1, \underline{\mathrm{N}}=235)=.26, \underline{\mathrm{p}}>.05\right)$.

Preliminary analyses were conducted to assess whether there were differences between the lesbian and heterosexual groups. A t-test indicated that there was a significant difference between age in the two groups $(\underline{\mathrm{t}}(234)=7.58, \underline{\mathrm{p}}<.05)$. However, there was not a significant difference between the two groups with respect to compliance $\left(\mathrm{X}^{2}(1, \underline{\mathrm{N}}=235)=.26, \underline{\mathrm{p}}>.05\right)$ nor with age and compliance $(\underline{\mathrm{t}}(234)$ $=1.77, \underline{\mathrm{p}}>.05)$

\section{Hypotheses Testing}

To test the hypotheses in question, the additional three barrier items and two self-efficacy items for the lesbian participants were dropped in order to make the items for each group comparable. The average score for each component was used for all analyses.

The first hypothesis states that the HBM will be a significant predictor of whether women comply with recommended guidelines for Pap smears. A logistic regression was computed to test this hypothesis, with compliance categories regressed on the HBM. This analysis indicated that all of the components of the HBM, considered simultaneously, were significant predictors of whether women comply with recommended guidelimes for Pap smears $\left(X^{2}(5, \underline{N}=235)=33.07, \underline{p}<.01\right)$.

Hypothesis two predicted that all of the components would make unique 
contributions to whether women comply with recommended guidelines. A logistic regression for the full model and the full model, with the component in question deleted for each separate run, indicated that self-efficacy and barriers were the only components that made unique contributions to the model (see Table 4).

Insert Table 4 about here

The third hypothesis stated that each component of the model would significantly predict whether women comply with recommended guidelines. Logistic regressions were computed separately for each component. Self-efficacy $\left(X^{2}(1, \underline{N}=\right.$ $238)=25.56, \underline{p}<.01)$ and barriers $\left(X^{2}(1, \underline{N}=238)=14.31, \underline{p}<.01\right)$ were found to be the only components that significantly predicted whether women complied with the recommended guidelines (see Table 5).

Insert Table 5 about here

Hypothesis four predicted that the barriers component would have the strongest correlation of all the components with respect to compliance with recommended guidelines. Separate point-biserial correlations were computed for each of the components of the HBM. The results indicated that self-efficacy and barriers had the strongest correlations with compliance (see Table 6). The more self-efficacy 
Insert Table 6 about here

the participant reported, the more likely she was to comply with recommended guidelines for Pap smears $\left(\underline{\underline{r}}_{b}(235)=.34, \underline{p}<.01\right)$. Whereas, the more barriers the participant reported, the less likely she was to comply with recommended guidelines $\left(\underline{I}_{b}(238)=-.25, \underline{p}<.01\right)$. Further analysis was conducted to assess whether there was a significant difference between the compliance and barriers correlation and the compliance and self-efficacy correlation, using a test of the significance of the difference between correlations of two variables with a third variable (Guilford \& Fruchter, 1978, p. 164). This analysis indicated that there was no significant difference found between these correlations $\left(t_{d r}=1.34, p>.05\right)$. To test whether the correlations for these two components were different in magnitude from the other components of the HBM, the above test was also performed using the correlations computed for compliance with barriers and compliance with benefits. The results indicated that there was a significant difference $\left(t_{d t}=1.81, p<.05\right)$. Therefore, hypothesis 4 was not supported. The correlations between self-efficacy and compliance and barriers and compliance were not significantly different from each other, and yet, were significantly different from the correlations between compliance and the other components of the HBM. This indicates that both self-efficacy and 
barriers have similarly high correlations and that these correlations are significantly greater than the correlations with the other components of the model.

The fifth hypothesis predicted that there would be interactions between the components of the HBM and sexual orientation, with respect to compliance with recommended guidelines. Considering there was a significant difference between the ages of the lesbians and heterosexual women, it was necessary to control for age in the analysis. Separate logistic regressions were conducted with sexual orientation (either lesbian or heterosexual) and age entered in the first step. Table 7 reports the separate

Insert Table 7 about here

regressions. Each variable was entered with the interaction term immediately following. The analysis indicated that once again, only self-efficacy and barriers were found to be significant at $p<.01$. Contrary to predictions, there were no significant interactions found. That is, the model predicts compliance in the same way for both lesbian and heterosexual women.

Throughout all of the analysis conducted to test the hypotheses in question, self-efficacy and barriers were found to be the most predictive components of the HBM. Figure 2 shows the percentage of compliance as a function of high/low categorization on these components. 
Discussion

The present study was designed to investigate whether there is a difference between heterosexual and lesbian women in obtaining gynecological exams. The Health Belief Model (HBM) was tested to investigate first, whether the model itself is predictive of obtaining gynecological exams, and second, to investigate which components of the model are most predictive.

Consistent with previous research (Murray \& McMillan, 1993; Janz \& Becker, 1984), the HBM was found to be a significant predictor of health behavior, specifically whether women complied with the recommended guidelines for Pap smears. There was no difference found between lesbian women and heterosexual women in respect to compliance with the recommended guidelines. Considering that there were no interactions found between the heterosexual and lesbian women, this implies that the HBM model used for the present study is predictive for women in general, regardless of sexual orientation.

\section{Limitations / Future Studies}

Although the HBM was found to be a significant predictor of compliance for both groups of women, the analyses indicated that the most important components of the model were self-efficacy and perceived barriers. It appears that the more selfefficacy women have, the more likely it is that they will comply with recommended guidelines for Pap smears. Whereas, the more barriers the women perceived, the less likely they are to comply. The present study implies that the process of compliance 
may be the same for both heterosexual and lesbian women regardless of age.

However, since the present analyses dropped the extra items for the lesbian sample, it is important that future studies attempt to identify the unique factors that promote selfefficacy and reduce barriers among both groups.

Considering that there have been few studies using self-efficacy as a component of the HBM, the finding that the component has such predictive power was not expected. Even though these items were internally consistent $(\alpha=.61)$, it is difficult to assess whether the items were measuring the construct of self-efficacy. Future studies should focus on the reliability and validity of items measuring selfefficacy and their applicability in the study of health behavior and compliance. If it is found that self-efficacy can predict health compliance behaviors, efforts can be made to investigate how attitudes and behaviors related to self-efficacy can be increased. As predicted, and consistent with past studies (Murray \& McMillan, 1993; Janz \& Becker, 1994), the perceived barriers scale was found to be a significant predictor of health behavior. The cumulative results of all these studies, including the present one, indicate that the more barriers individuals perceive to performing a health behavior, the less likely it is that the behavior will be performed. Thus, perceived barriers may be the component which prevents women from complying with recommended guidelines for obtaining gynecological exams. It would appear that if future studies can identify what specific barriers women perceive, efforts can be made to address and overcome these barriers and, in turn, promote health and longevity. 
Perceived severity and perceived susceptibility were found not to be significant predictors of compliance even though their scales were found to be reliable. Future studies would benefit from investigating these components further to attempt to identify whether the women do not perceive the threats as severe, or perceive that they are not susceptible, perhaps due to a lack of knowledge or lack of experience from friends or relatives. This information would be important for developing educational interventions for women about the health risks of not obtaining gynecological care.

All but one of the alpha coefficients for the components of the HBM indicated that the items were fairly consistent for each component. However, the alpha coefficient for benefits was low $(\alpha=.44)$. Although these items were drawn from previous studies, they were not internally consistent in the present study. The items may have been measuring constructs other than what the individual may perceive as a benefit. For example, the item "A Pap smear can identify abnormal cervical cells" could be perceived as a question seeking factual information rather than attitude information. Future studies should take this possibility into consideration and make attempts to develop questions that more accurately identify attitudes toward certain benefits of performing health behaviors.

There are many limitations to the current study. Generalizability of the sample to the general women's population may be difficult since the present sample consisted only of women from a southwestern city. Future studies should focus on obtaining a larger sample of women from a variety of geographical locations since health care 
policies, providers, and procedures may vary. Conducting a comparison study of different geographical locations could indicate if health behaviors of women vary depending upon region. Such studies would prove to be valuable in the respect that researchers would know whether recommendations should be considered on a local level or a national level.

The potential lack of generalizability of the lesbian population also presents limitations to the current study. Because of fear of discrimination and homophobia, many women may resist identifying themselves as a lesbian, which may have affected the response rate of this study. The present study, as well as others conducted, sample only those women who are accessible, thus creating methodological difficulties for finding participants and drawing conclusions for a larger group of women. Due to this constraint, it is difficult to assess whether the sample obtained is representative of lesbians in general. Therefore, as long as social pressures exist which prevent women from self-identifying as lesbians, obtaining a representative sample of lesbians will be difficult for researchers. Even though $75 \%$ of the lesbian women in the present study complied with the guidelines, past research has suggested that lesbians are dissatisfied with the present health care system and therefore avoid using it (Lucas, 1992; Stevens 1992). Since lesbians may be overlooked and underserved in the medical community, future studies should attempt to address the unique concerns of this population.

Considering that the present sample of heterosexual women was obtained only from a university setting, this also presents some limitations for generalizability to the 
larger female population. Health compliance differences may exist among various educational backgrounds. Since some of the women in the present study received credit for participating, it is difficult to assess their motivation for responding to the questionnaire. With respect to these concerns, efforts should be made in future studies to obtain a sample of heterosexual women from sources other than the traditional university setting which might provide a better a variety of educational backgrounds, levels, and experiences.

Future studies should address the issue of data collection method when comparing two groups such as lesbian and heterosexual women. When comparing groups, it is essential to make attempts to obtain the data using the same methods; the present study failed to do so, which has potential effects on the conclusions drawn from this study. Potentially, using a community mailing list could introduce greater heterogeneity with respect to demographics, whereas the university setting may produce more homogeneity with respect to demographics.

Other issues, (e.g., response rate, reliability, etc.) may also be affected by method of data collection. For instance, the lesbian participants may have had more of an opportunity to self-select. For example, some of the lesbian women may not have responded to the questionnaire because they did not feel as if it applied to them, since they do not obtain gynecological exams. The university participants, however, had extrinsic motivation to promote their participation, namely, course credit. In order to 
truly compare lesbian and heterosexual women, it is important that the method of data collection be considered and held as consistent as possible.

Another consideration of the present study is the method of classification for compliance. In the present study, the participants were categorized as compliant if they indicated that they had had two or more Pap smears in the past six years. This method could be considered conservative since $35 \%$ of the women in the present study indicated that they had had only two Pap smears in that time frame. Future studies should re-evaluate medical recommendations and assess whether this is an appropriate rate of compliance. Another recommendation would be to extend the range of years to 10 or 12 , to assess whether they truly comply or whether the responses were based on circumstances at the time of responding. For example, a woman who is experiencing menstrual problems may have had two Pap smears within the past year, but may not routinely comply with the recommendations. Studies may also benefit from collecting supporting data (e.g., medical records) regarding gynecological care.

One important factor of health prevention and compliance with recommended guidelines is having the knowledge that early detection and prevention is necessary. Just as a young child may not know that the street can be dangerous, a woman may not understand the importance of regular Pap smears unless she is taught. Although not found in this study (perhaps because of sample size limitations) women younger than 20 years old and lesbian women may be the least likely to comply with 
recommended guidelines. One reason for greater non-compliance among younger women may be that this age group is not informed about the guidelines and will have had less time than older women to learn about the compliance recommendations. Non-compliance among lesbians may be due to the misperception that regular Pap smears are unnecessary unless one is heterosexually active (Buenting, 1992), or they may fear discrimination based on sexual preference. Future studies should also attempt to obtain a larger sample of women with varying ages and address issues involving knowledge of gynecological care and preventive measures.

\section{Conclusion}

Cervical cancer is just one example of a disease that if detected in early stages can be almost $100 \%$ curable. Without adequate health care, such diseases could go undetected and lead to death. Therefore, it is essential that research continue to investigate health behaviors associated with screening and early detection.

Psychological models should be included in the investigations since they can assist with understanding health behaviors. Research should attempt to identify why women comply, or do not comply, with recommended guidelimes associated with cervical screening. Once research has identified constructs which are predictive of screening behavior, information can be provided to the medical community in attempts to address these issues for women.

It is critical that women be educated about the risks of certain behaviors, the risk profiles associated with particular cancers, and those steps most likely to lead to 
prevention or early detection (White, 1993). Education may be a primary role of health professionals (White), but it is important that health care provide environments that are perceived as being safe in order for this information to be given. Health professionals must be educated about alternative lifestyles and their unique concerns. Methods of verbal and written assessments that do not presume lifestyle nor sexual activity, must be developed and implemented, since these messages may themselves be barriers to seeking care. It is necessary to investigate other means of educating women about prevention and early detection, either through educational systems or public broadcasting.

As long as there are diseases which can be treated or cured in the early stages of diagnosis, and these diseases are going undetected, it is essential for research in health behavior to contimue. It is important that women are educated about screening and early detection because of their life-saving potential. Above all, it is important that health professionals provide an environment for all women, no matter what education level, socio-economic status, or lifestyle, that is conducive to women's willingness to obtain adequate health care. 
References

Ajzen, I., \& Fishbein, M. (1980). Understanding attitudes and predicting behavior. Englewood Cliffs, NJ: Prentice Hall.

Bandura, A. (1986). Social Foundations of Thought and Action: A Social Cognitive Theory. Englewood Cliffs, NJ: Prentice-Hall.

Bausell, R. B. (1986). Explaining preventive behavior: The development and evaluation of a model. Evaluation and the Health Professions, 9 (1), 3-19.

Becker, M. H. \& Maiman, L. A. (1975). Sociobehavioral determinants of compliance with health and medical care recommendations. Mental Care, 13, 10-24.

Bernard, L. C., \& Krupat, E. (1994). Health Psychology. Fort Worth: Harcourt Brace College.

Buenting, J. A. (1992). Health life-styles of lesbians and heterosexual women. Health Care for Women International, 13, 165-171.

Champion, V. L. (1984). Instrument development for health belief model constructs. Advances in Nursing Science, 6 (3), 73-85.

Champion, V. L. (1990). Breast self-examination in women 35 and older: A prospective study. Journal of Behavioral Medicine, 13 (6), 523-538.

Dardick, L, \& Grady, K E. (1980). Openness between gay persons and health professionals. Annals of Internal Medicine, 93, 115-119.

Fishbein, M., \& Ajzen, I. (1975). Belief, attitude, intention and behavior: An introduction to theory and research. Reading, MA: Addison-Wesley. 
Guilford, J. P., \& Frutcher, B. (1978). Fundamental Statistics in Psychology and Education (6th Ed.). New York: McGraw-Hill, Inc.

Harrison, J. A., Mullen, P. D., \& Green, L. W. (1992). A meta-analysis of studies of the Health Belief Model with adults. Health Education Research, 7, 107 116.

Hester, N. R, \& Macrina, D. M. (1985). The health belief model and the contraceptive behavior of college women: Implications for health education. Journal of American College Health, 33, 245-252.

Holleb, A. I., Fink, D. J., \& Murphy, G. P. (1991). American Cancer Society Textbook of Clinical Oncology. Atlanta, GA: The American Cancer Society, Inc.

Janz, N. K, \& Becker, M. H. (1984). The Health Belief Model: A decade later. Health Education Quarterly, 11 (1), 1-47.

Johnson, S. R, Guenther, S. M., Laube, D. W., \& Keettel, W. C. (1981). Factors influencing lesbian gynecological care: A preliminary study. American Journal of Obstetrics and Gynecology, 140, 20-28.

Johnson, S. R, \& Palermo, J. L. (1984). Gynecologic care for the lesbian. Climical Obstetrics and Gynecology, 27, 86-93.

Kirscht, J. P. (1983). Preventive health behavior: A review of research and issues. Health Psychology, 2 (3), 277-301.

Knopf, A. (1976). Changes in women's opinions about cancer. Social Science and Medicine, 10, 191-195. 
Lucas, V. A. (1992). An investigation of the health care preferences of the lesbian population. Health Care for Women International, 13, 221-228.

Maddux, J. E., \& Rogers, R. W. (1983). Protection motivation and self-efficacy: A revised theory of fear appeals and attitude change. Journal of Experimental Social Psychology, 19, 469-479.

McCaul, K D., Sandgren, A. K, O'Neill, H. K, \& Himsz, V. B. (1993). The value of the theory of planned behavior, perceived control, and self-efficacy expectations for predicting health-protective behaviors. Basic and Applied Social Psychology, 14 (2), 231-252.

Mikhail, B. (1981). The Health Belief Model: A review and critical evaluation of the model, research, and practice. Advances in Nursing Science, 4 (1), 65-82.

Murray, M., \& McMillan, C. (1993). Health beliefs, locus of control, emotional control and women's cancer screening behaviour. British Journal of Clinical Psychology, 32, 87-100.

Norman, S. A., Talbott, E. O., Kuller, L. H., Stolley, P. D., Dunn, M. S., Baffone, K, Klionsky, B., \& Weinberg, G. B. (1991). The relationship of Papanicolaou testing and contacts with the medical care system to stage at diagnosis of cervical cancer. Archives of Internal Medicine, 151, 58-64.

O'Brien, S., \& Lee, C. (1990). Effects of videotape intervention on Pap Smear knowledge, attitudes, and behavior. Behaviour Change, 7 (3), 143-150. 
Prentice-Dunn, S., \& Rogers, R. W. (1986). Protection motivation theory and preventive health: Beyond the health belief model. Health Education Research, 1 , 153-161.

Robertson, M. M. (1992). Lesbians as an invisible minority in the health services arena. Health Care for Women International, 13, 155-163.

Ronis, D. L. (1992). Conditional health threat: Health beliefs, decisions, and behaviors among adults. Health Psychology, 11 (2), 127-134.

Sarafino, E. P. (1994). Health Psychology: Biopsychosocial Interactions (2nd Ed.). New York: John Wiley \& Sons, Inc.

Smith, E. M., Johnson, S. R, \& Guenther, S. M. (1985). Health care attitudes and experiences during Gynecologic care among lesbians and bisexuals. American Journal of Public Health, 75 (9), 1085-1087.

Stein, J. A, Fox, S. A., Murata, P. J., \& Morisky, D. E. (1992). Mammography usage and the health belief model. Health Education Quarterly, 19 (4), 447-462.

Stevens, P. E. (1992). Lesbian health care research: A review of the literature from 1970 to 1990. Health Care for Women International, 13, 91-120.

Stevens, P. E. (1994). Protective strategies of lesbian clients in health care environments. Research in Nursing and Health, 17, 217-229. 
Stevens, P. E., \& Hall, J. M. (1988). Stigma, health beliefs, and experiences with health care in lesbian women. Image: Journal of Nursing Scholarship, 20 (2), 6973.

Taylor, S. (1991). Health Psychology (2nd Ed.). New York: McGraw-Hill, Inc.

Trippet, S. E., \& Bain, J. (1990). Preliminary study of lesbian health concerns. Health Values, 14, 29-36.

Trippet, S. E., \& Bain, J. (1992). Reasons American lesbians fail to seek traditional health care. Health Care for Women International, 13, 145-153.

Weinstein, N. D. (1993). Testing four competing theories of health-protective behavior. Health Psychology, 12, 324-333.

White, L. N. (1993). An overview of screening and early detection of Gynecologic malignancies. Cancer Supplement, 71, 1400-1405.

White, J., \& Levinson, W. (1993). Primary care of lesbian patients. Journal of General Internal Medicine, 8, 41-47.

Yoder, L., \& Rubin, M. (1992). The epidemiology of cervical cancer and its precursors. Clinical Review, 19, 485-493.

Zeidenstein, L. (1990). Gynecological and childbearing needs of lesbians. Journal of Nurse-Midwifery, 35, 10-18. 
Appendix A

Questionnaire

Section I: Health coverage and experiences...

Do you have health coverage or insurance?

yes no

If yes, what type of insurance:

Medicare

Medicaid

__ HMO (Health Maintenance Organization; e.g., Health Plan of

Nevada, FHP, Humana Health Plan, etc.)

Private insurance

Combination of above

Other

Does your insurance require you to declare a primary care physician (PCP)?

yes

no

If yes, what specialty of physician did you declare?

Family Practice

Internist

OB-Gyn (Obstetrician/Gynecologists)

How did you make this decision? preferred that specialty referred by a friend assigned PCP by

other health coverage

When you are having health problems, do you: go to an urgent care climic schedule an appointment with a primary care physician

__ schedule an appointment with a specialist (physician dealing specifically with the problem) go to a health department (climic) go to a nontraditional clinic (i.e., naturopath, acupuncture) go to a women's centered climic go to a women's climic other do nothing

Have you ever needed to see a doctor but did not go? yes no 
Appendix A cont.

Has a health professional (nurse, physician, etc.) ever asked you directly (either verbally or on a health history form) about your sexual orientation? yes no

Have you ever been a victim of discrimination by a health professional because of...
gender?
sexual orientation?
$\begin{array}{rr}\text { yes } & \text { no } \\ \text { yes } & \text { no } \\ \text { yes } & \text { no }\end{array}$
single parenting?

Other?

In what form(s) has this discrimination taken place?

At what age did you become sexually active?

(please write-in

estimated age)

don't remember age

have never been sexually

active

Have you ever had a gynecological exam?

_yes _no

When was your last gynecological exam?

What was the primary reason for that appointment? yearly Pap smear infection birth control conception counseling irregular menstrual cycle other pain or irregular cramps

other

Have you ever had a Pap smear? yes no don't know

When was the last time that you had a Pap smear?

How many Pap smears have you had in the past five years?

Has a health professional ever informed you that you have had a positive Pap smear (irregular cells identified)? yes no don't know (Appendix A continued on next page.) 
Appendix A cont.

Have you ever had a breast exam performed by a health professional?

_ yes __ no _ _ don't know

Have you ever had a mammogram (x-ray of the breast)?

_ yes ___ no _ don't know

How many mammograms have you had in your lifetime?

Have you ever been pregnant? yes no

Have you had a hysterectomy?

yes no

Section III: Information about yourself..

Age

Relationship Status: single (living alone) living together as married legally married

legally divorced
__ legally widowed
other

Sexual Orientation:

___ bisexual heterosexual lesbian

Educational Level:

No school completed 1st-8th grades completed Some high school, no diploma

High school graduate (or equivalent, GED)

Some college, no degree

Associate Degree (1-2 yr. occupational or academic program)

Trade school (dealer school, cosmetology etc.)

Four year college graduate other

Advanced degree (including masters, professional degree, doctorate)

(Appendix A continued on next page.) 
Appendix A cont.

Employment:

Employed full time

___ Employed part time

Not employed

Student

___ Student and employed

Total annual gross income (just inchude yourself):

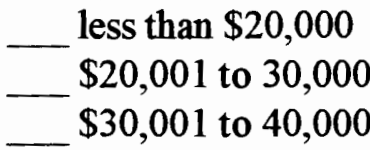

$\$ 40,001$ to 50,000

$\$ 50,001$ to 75,000

$\$ 75,001$ or more

Additional comments you would like to add about your gynecological health care experiences: 
Appendix B

Items to Assess HBM Components

PERCEIVED THREAT:

Perceived Susceptibility

- My chances of getting cervical cancer are high.

- My physical health makes it likely that I will get cervical cancer.

- My sexual behavior makes it likely that I will be infected with a Sexually

Transmitted Disease.

- I feel that my chances of getting cancer in the future are high.

Perceived Severity

- The thought of cervical cancer scares me.

- I am afraid to even think of cancer.

- The thought of Sexually Transmitted Diseases scares me.

- The thought of having an abnormal Pap smear scares me.

- If I were to get cancer my whole life would change.

- Cervical cancer can lead to death if it goes undetected.

\section{EFFICACY OF BEHAVIOR:}

Perceived Benefits

- If cervical cancer is detected early it can be successfully treated.

- Having a gynecological exam will prevent future problems for me.

- I have a lot to gain by having a gynecological exam.

- A Pap smear can indicate abnormal cervical cells.

Perceived Barriers (See Appendix C)

\section{SELF-EFFICACY:}

- I can keep my appointment to have a gynecological exam even if I have to go alone.

- I can give accurate information to a health professional even when it pertains to my sexuality.

- I can keep my appointment for a gynecological exam even if I am uncomfortable with the exam.

- I can have cervical screening tests annually even if I am not having health problems.

- I can see a health professional annually even if I have to take time off of school/work. 
Appendix C

Barrier Items

Resources:

- Do you have health coverage or insurance?

- Going to a doctor costs a lot of money.

- I do not have the money to go to a health professional.

- I do not have transportation to get to a gynecological exam.

Information:

- Women only need to go to the gynecologists if they are having health problems.

- If women are not using a birth control method, there is no need to go to the gynecologist.

- It is important that I provide health professionals with accurate information about myself.

Nature of Examination:

- I would be embarrassed by the examination and tests that might be performed in a gynecological exam.

- The examination and tests that are performed in a gynecological exam might be uncomfortable.

- The examination and tests that are performed in a gynecological exam might be painful.

Miscellaneous:

- The medical profession is not informed about my life-style.

- I would be afraid of the findings; if something were really wrong I wouldn't want to know about it.

- I do not trust traditional medicine.

- Having a gynecological examination takes time out of my schedule.

- I do not like going alone to have a gynecological exam.

- I think that health professionals I have seen are informed about women's health issues.

- Health professionals are not informed about my lifestyle.

- I have experienced discrimination by a health professional.

- I think that the health professionals I have seen are informed about same-sex relationships. 
Appendix D

Extra Items for Lesbian Questionnaire

Have you ever disclosed your sexual orientation to a health professional?

_. yes no no

What influenced your decision?

If given a choice, would you prefer a:

male physician

female physician

male "openly gay" physician

female "openly gay" physician

best qualified physician; gender and sexual orientation not important

other

Self-Efficacy:

- I can disclose my sexual orientation to a health professional.

- I can deal with sexual biases against me in the health care environment.

Barriers:

- I am afraid that if a medical professional knew I was a lesbian I would be discriminated against.

- I would be afraid to disclose my sexual orientation to a health professional if I knew that it would be recorded in my medical records. 
Appendix E

Compliance Recommendations

Recommendations:

From onset of sexual activity or age 18 , (which ever comes first) to age 65 , Pap tests should be performed every 1-3 years. Adequate tests should be performed annually until three consecutive tests are normal, after which, reducing the frequency can be considered.

Oregon Breast \& Cervical Cancer Coalition. (1994). Provider's Guide: Consensus Screenimg Guidelimes for Breast \& Cervical Cancer [Brochure]. Portland, OR: Oregon Health Division. 


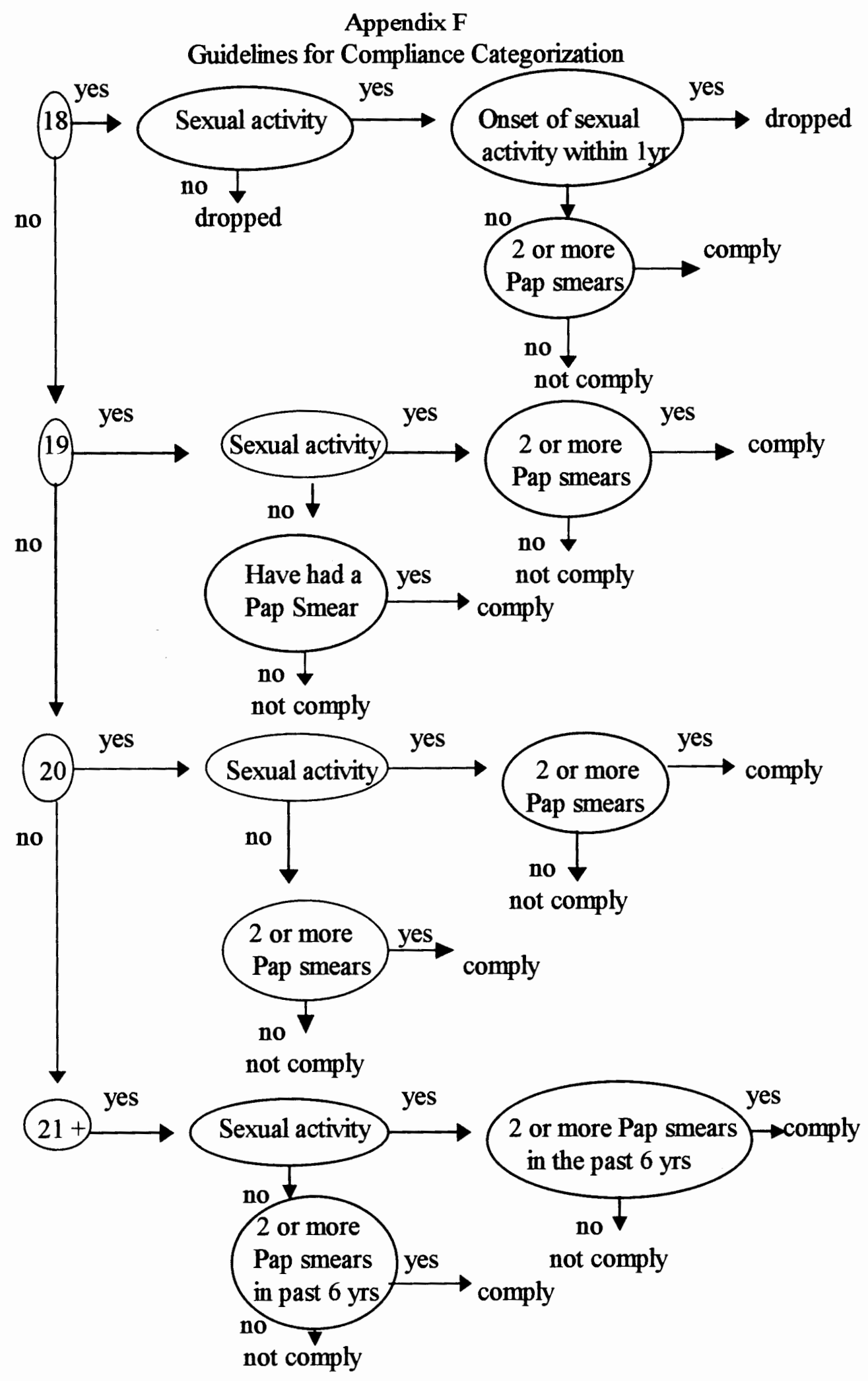


Table 1

Frequency of Participants in Each Demographic Variable

Total

$\frac{N}{238} \quad \frac{\text { Lesbian }}{168} \quad \frac{\text { Heterosexual }}{70}$

Relationship Status

Single (living alone)

$\begin{array}{lll}84 & 57 & 27\end{array}$

Living together as married

$103 \quad 97$

6

Legally married

$27 \quad 2$

25

Legally divorced

$7 \quad 1$

10

149

Other

22

6

1

Missing value

0

Education Level

Some high school

High school degree (GED)

$\begin{array}{lll}3 & 2 & 1 \\ 27 & 24 & 3 \\ 64 & 40 & 24 \\ 17 & 12 & 5 \\ 6 & 5 & 1 \\ 52 & 36 & 16 \\ 67 & 47 & 20 \\ 2 & 2 & 0\end{array}$

Employment

Some college (no degree)

Associate degree

Trade school

4 yr. college degree

Advanced degree

Missing value

24

1

16

0

Full time

$\begin{array}{lll}154 & 135 & 19\end{array}$

Part time

$18 \quad 8$

10

Not employed

$12 \quad 11$

1

Student

130

13

Student and employed

325

27

Retired

$7 \quad 7$

Missing value

22

0

0

Gross Income

less than $\$ 20,000$

$\begin{array}{lll}64 & 22 & 42\end{array}$

$\$ 20,001$ to 30,000

$56 \quad 40$

16

$\$ 30,001$ to 40,000

$45 \quad 41$

4

$\$ 40,001$ to 50,000

$33 \quad 31$

2

$\$ 50,001$ to 75,000

$23 \quad 22$

1

$\$ 75,001$ or more

129

3

Missing value

53

2 
Table 2

Cronbach's Alpha Coefficients for the Subscales of the HBM

Subscale

Barriers

Lesbian

Heterosexual

Benefits

Self-efficacy

Lesbian

Heterosexual

Severity

Susceptibility
Alpha

.75

.65

.44

.68

.61

.71

.67 
Table 3

Compliance Percentages as a Function of Category

Comply

$\underline{N}$

Total

Lesbian

Heterosexual
238

70

168
$\%$ Comply

\% Not

24

25

22

76

75

78

Age

$$
\begin{aligned}
& 18-25 \\
& 26-33 \\
& 34-41 \\
& 42-49 \\
& 50-58 \\
& 59-78
\end{aligned}
$$

33

38

62

63

26

11

67

33

68

32

18

82

25

75

23

77
91

9

Health Coverage

Yes

No

$\begin{array}{ll}70 & 30\end{array}$

Education Level

Some high school 3

High school degree (GED) 27

67

Some college (no degree)

Associate degree

Trade school

6

4 yr. college degree

6

Advanced degree

52

67

75

50

50

78

22

79

21

Relationship Status

Single (living alone)

84

103

Legally married

Legally divorced

Legally widowed

Other
27

7

1

14
68

33

79

89

100

0

64
21

11

0

100

36 
Table 4

Logistic Regression for Full Model

Variable

Full model

Barriers

Benefits

Self-efficacy

Severity

Susceptibility

constant
Beta

$\underline{\text { Wald } \mathrm{X}^{2}}$

$\underline{\text { df }}$

Significance

$-.78$

$-.17$

.84

.14

.16

$-1.88$
4.94

.68

14.68

1.00

1.23

.95
03

.41

.00

.32
.33 
Table 5

Separate Logistic Regressions for Each Component of the HBM

\begin{tabular}{lcccc}
\hline Component & $\underline{\text { Beta }}$ & $\underline{\text { Wald X }}$ & $\underline{\text { df }}$ & $\underline{\text { Significance }}$ \\
Barriers & -1.13 & 12.92 & 1 & .00 \\
Benefits & .28 & 2.66 & 1 & .10 \\
Self-efficacy & .89 & 21.77 & 1 & .00 \\
Severity & .13 & 1.13 & 1 & .29 \\
Susceptibility & .07 & .27 & 1 & .60 \\
\hline
\end{tabular}


Table 6

Point Biserial Correlations between Subscales of the HBM and Compliance

\begin{tabular}{|c|c|c|}
\hline Subscale & \multicolumn{2}{|c|}{ Compliance } \\
\hline Barriers & -.25 & $\mathrm{p}=.00$ \\
\hline Benefits & .11 & $p=.10$ \\
\hline Self-efficacy & .34 & $\underline{p}=.00$ \\
\hline Severity & .07 & $\mathrm{p}=.29$ \\
\hline Susceptibility & .03 & $\underline{p}=.61$ \\
\hline
\end{tabular}


Table 7

Logistic Regression Analysis to Assess Interaction of Components with Sexual Orientation Controlling for Age $(\mathrm{N}=238)$

Variable

Entered

Self- Efficacy

Barriers

Benefits

Severity

Susceptibility
Additive $X^{2}$ for

Model

30.00

21.54

9.46

10.24

7.98

9.89

3.49

.78

6.40

.25 p value

.84

$\begin{array}{ll}.88 & .30\end{array}$

.38

.62

.07 
Figure 1. The Health Belief Model.

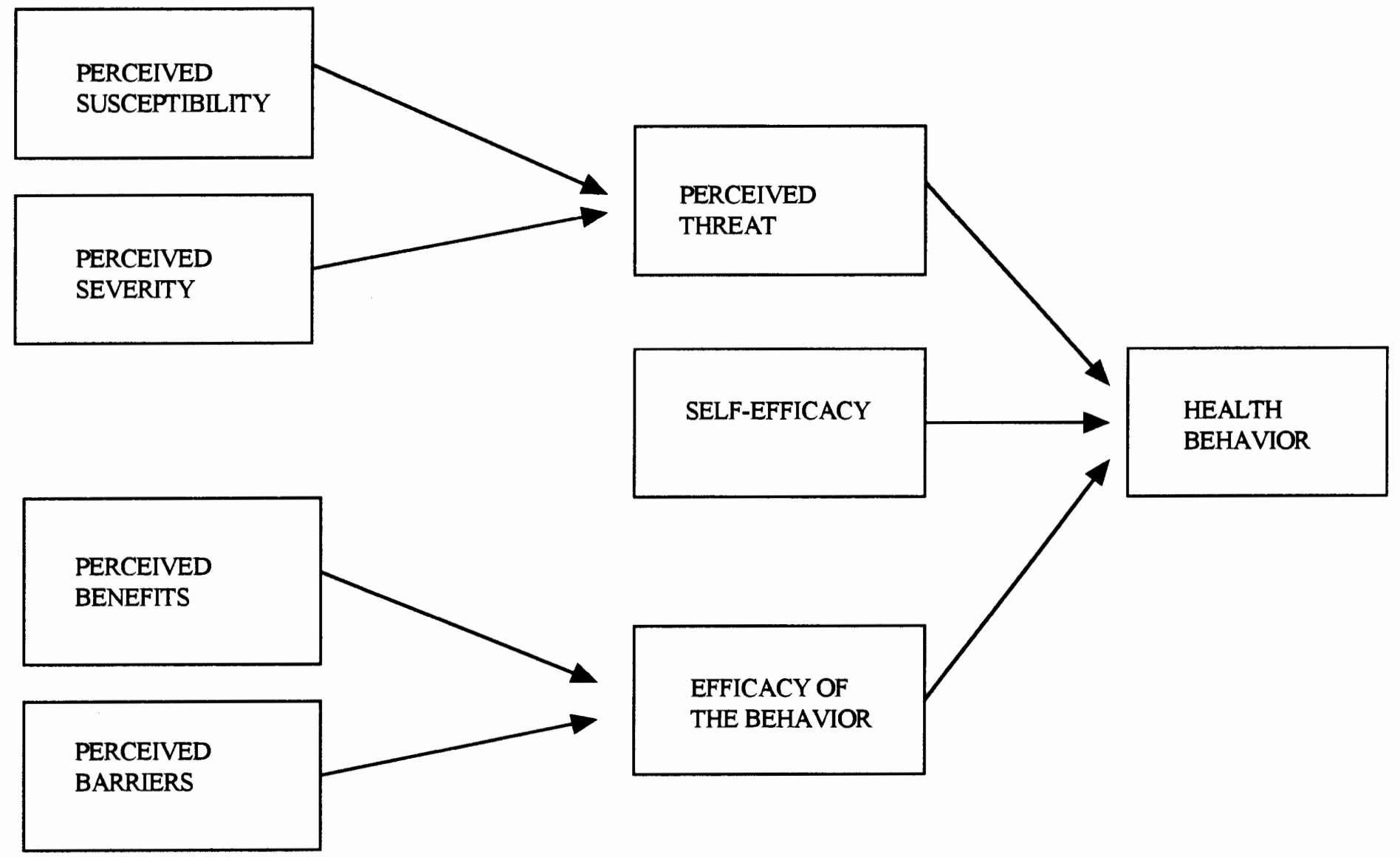


Figure 2. Compliance as a Function of Barriers and Self-Efficacy

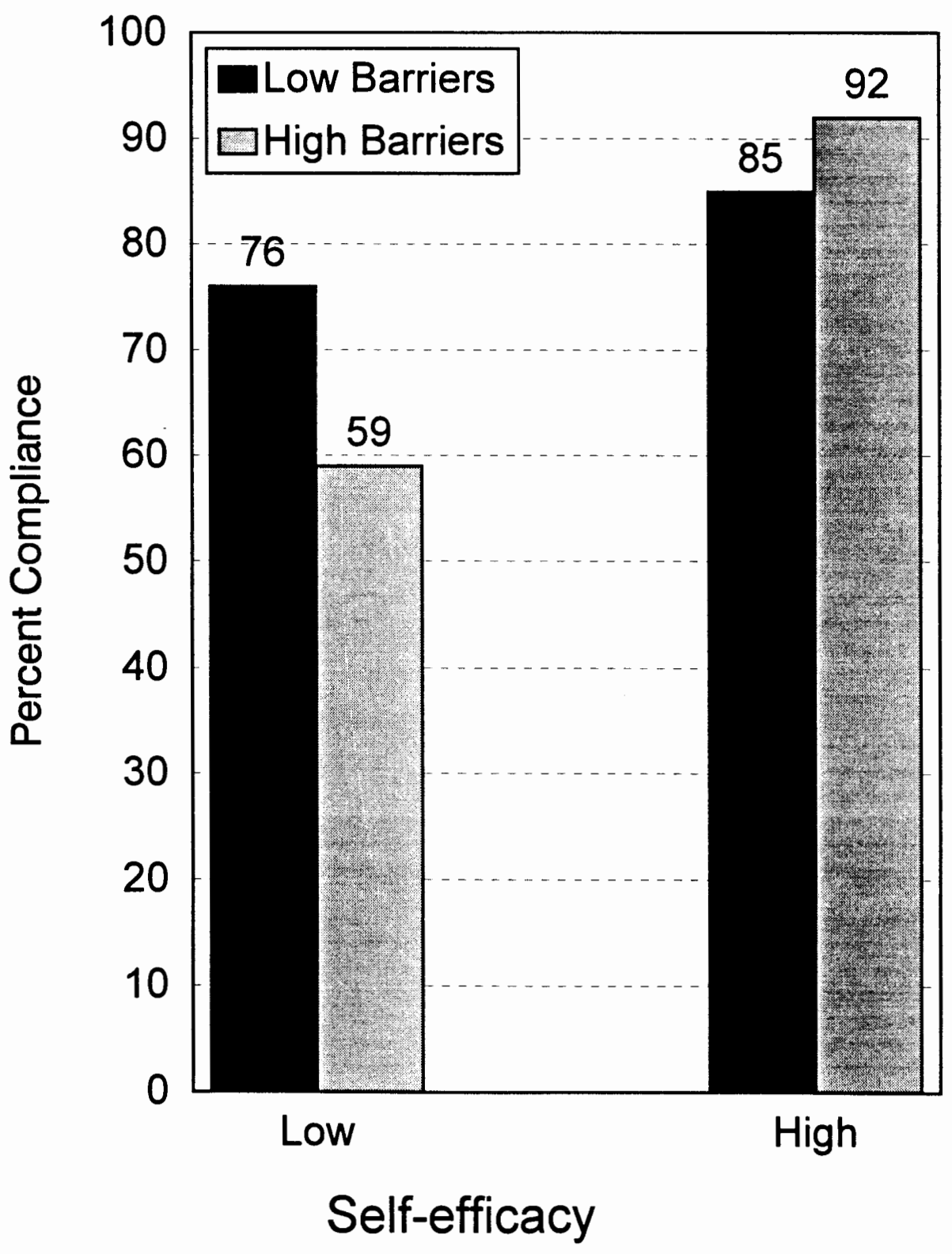

